\title{
Estado do Conhecimento: conceitos, finalidades e interlocuções
}

State of knowledge: concepts, purposes and dialogues

\section{Marília Costa Morosinia Cleoni Maria Barboza Fernandes ${ }^{b}$}

\section{Editor}

Maria Inês Côrte Vitoria PUCRS, RS, Brasil

\section{Equipe Editorial}

Pricila Kohls dos Santos PUCRS, RS, Brasil

Marcelo Oliveira da Silva PUCRS, RS, Brasil Carla Spagnolo PUCRS, RS, Brasil Rosa Maria Rigo PUCRS, RS, Brasil

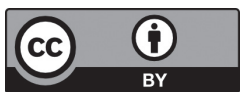

A matéria publicada neste periódico é licenciada sob forma de uma Licença Creative Commons - Atribuição 4.0 Internacional. http://creativecommons.org/licenses/by/4.0/

\begin{abstract}
"Um acontecimento vivido é finito, ou pelo menos encerrado na esfera do vivido, ao passo que o acontecimento lembrado é sem limites, porque é apenas uma chave para tudo que veio antes e depois."
\end{abstract}

WALTER BENJAMIN

"Escrever é isso aí: interlocução."

MARIO OSORIO MARQUES

Z pedagógicas das autoras. Assumimos que o vivido foi delimitado no espaçotempo da constituição da Linha de Pesquisa II Formação, Políticas e Práticas, do Programa de Pós-Graduação em Educação da PUCRS, mas que o acontecimento lembrado é sem limites e o consideramos fundamental no espaçotempo ainda por viver. E para que esse acontecimento lembrado se torne movimento reflexivo para depois, trazemos a compreensão de que escrever é isso aí: interlocução.

Nossa interlocução inicia pelo reconhecimento da importância da escritura na formação do professor/pesquisador, e para além deste fato, para a formação do cidadão. A escritura mais do que uma forma da comunicação humana, configura-se em condição de registro

a Doutora em Educação. Tem estudos de Pós-Doutorado pela Universidade de Texas nos EEUU. Coordenadora do Centro de Estúdios em Educação Superior (CEES) da Pontifícia Universidade Católica do Rio Grande do Sul, Brasil. Investigadora do National Council of Reseach (CNPq).

b Professora pesquisadora do Programa de Pós-Graduação em Educação da Faculdade de Educação da Pontifícia Universidade Católica do Rio Grande do Sul (PUCRS), Porto Alegre, RS, Brasil. E-mail: <cleoni.fernandes@pucrs.br>. 
do vivido histórico, social e culturalmente e, assim da possibilidade de reescrever a escrita e o caminho por viver (FERNANDES, 1999).

Na dimensão da escritura acadêmica, o cuidado com a produção de sentido tem um compromisso diferenciado da escrita literária que também busca a clareza e consistência, mas também o exercício da imaginação e recriação do texto. $\mathrm{Na}$ escritura acadêmica há uma necessidade de clareza e consistência da explicação - natureza epistêmica da Ciência e compreensão - natureza da Filosofia (FERNANDES, 2011). Evidente que nas duas dimensões acima apontadas, estão referidas a clareza, consistência e coerência do escrito - mesmo na possível irreverência do texto literário.

No trabalho acadêmico, o conhecimento e suas relações com a vida é nossa ferramenta de trabalho. Nesta perspectiva, compreender o conhecimento como produção histórico-cultural situado e datado nas estruturas de poder vigentes em cada espaçotempo é condição vital para escapar do conhecimento como um cadáver de informação - um corpo morto de conhecimento (SHOR E FREIRE, 1987, p. 15).

Nessa perspectiva, temos trabalhado com o estado do conhecimento como uma matéria formativa e instrumental que favorece tanto a leitura de realidade do que está sendo discutido na comunidade acadêmica, quanto em relação a aprendizagens da escrita e da formalização metodológica para desenvolvimento do percurso investigativo.

\section{Conceitos e processos ${ }^{1}$}

No entendimento, estado de conhecimento é identificação, registro, categorização que levem à reflexão e síntese sobre a produção cientifica de uma determinada área, em um determinado espaço de tempo, congregando periódicos, teses, dissertações e livros sobre uma temática específica. Uma característica a destacar é a sua contribuição para a presença do novo ${ }^{2}$ na monografia.

MOROSINI, M. C. 2014.

2 O novo pode advir de questões, tópicos ou áreas; da aplicação de ideias, métodos, approaches ou análises; ou do desenvolvimento ou aplicação de teorias, descrições teóricas ou approaches teóricos; ou invenção, desenvolvimento ou aplicação de métodos, ou approaches, técnicas computacionais ou tecnologias; ou da criação, descoberta ou utilização de dados, conjunto de dados, arquivos, informações, fontes ou recursos; ou da aplicação de ideias antigas, métodos, approaches ou análises a dados, materiais ou fontes; ou do desenvolvimento ou aplicação de análises, approaches analíticos, esquemas técnicos, modelos ou procedimentos estatísticos; da introdução de ideias, conexões, inferências, insights, interpretações, observações, perspectivas; ou da produção de conclusões, respostas, descobertas ou provas; ou da combinação ou síntese de coisas (experimentos, fatos, conhecimentos, modelo de pesquisa, problemas, fontes, tecnologias, construtos teóricos) de outros campos ou disciplinas (LOVITTS, 2007, p. 31). 
Nesta reflexão, faz-se necessário considerar que a construção de uma produção cientifica está relacionada não só à pessoa/pesquisador que a produz, mas a influências da instituição na qual está inserida, do país em que vive e de suas relações com a perspectiva global. Em outras palavras, a produção está inserida no campo científico e, consequentemente, em suas regras constitutivas, segundo as quais o

universo 'puro' da mais 'pura' ciência é um campo social como outro qualquer, com suas relações de força e monopólios, suas lutas e estratégias, seus interesses e lucros, mas onde todas essas invariantes se revestem de formas específicas. (BOURDIEU, 1983, p. 122 - grifos do original)

A prática na disciplina "Construindo o estado de conhecimento de sua tese ou dissertação" - Seminário Instrumental - estrutura-se nas fases metodológicas a seguir especificadas:

- Análise de textos sobre produção cientifica, seus princípios, políticas e condicionantes, na perspectiva nacional e internacional;

- Identificação da temática da tese ou da dissertação, com clarificação da pergunta de partida, e das palavraschave ligada ao tema;

- Leitura e discussão sobre produção científica no plano teórico e no empírico (teses, dissertações, livros, congressos);

- Identificação de fontes e constituição do corpus de análise.

O corpus de análise pode ser constituído a partir de: livros - produção amadurecida; teses e dissertações produção reconhecida junto aos órgãos de avaliação da produção nacional. Banco de todas as teses e dissertações produzidas no país com reconhecimento do governo - CAPES. As monografias constituidoras deste banco são advindas de programas legitimados pela comunidade cientifica da área. O corpus de analise pode ser constituído também por textos advindos de eventos da área, que congregam o novo, o emergente, e, na maioria das vezes, o pensamento da comunidade acadêmica.

A partir da constituição do corpus da análise, as fases seguintes deste seminário envolvem:

- Leitura flutuante do corpus de análise para a identificação dos textos;

- Construção da bibliografia anotada e da sistematizada;

- Seminários coletivos de discussão das temáticas individuais com a classe de estudantes e com os estudantes individualmente;

\footnotetext{
3 Num primeiro momento, constroem-se tabelas identificando o número do trabalho em seu veículo de publicação - anais de evento, banco de teses ou periódicos -, autor, instituição de origem, título do trabalho, palavras-chave, questões e objetivos de pesquisa, metodologia, e resumo. Posteriormente, criam-se arquivos compondo um banco de dados com os textos completos que abordam a temática
} 
- Proposição de possíveis categorias, a partir da análise de conteúdo (BARDIN, 1979) ou da análise textual discursiva (MORAES, GALLIAZZI, 2006);

- Novos seminários coletivos de discussão das temáticas individuais com a classe de estudantes, já com produção textual inicial;

- Entrevista com pesquisador ou professor da área ou orientador para a busca do entendimento do encontrado;

- Redação de texto, seguindo as normas de um artigo;

- Inscrição do aluno para apresentar trabalho de construção do estado de conhecimento, se possível, em algum seminário qualificado da área da produção textual;

- Apresentação individual final, ao grupo, em atividade de seminário.

A experiência educativa foi marcada pela aprendizagem colaborativa que se reflete em nível de estudante como: Permanência na faculdade; Habilidades de resolução de problemas; Retenção de conhecimento em longo prazo; Habilidades em grupo; Habilidades para criar; Assumir riscos intelectuais; Conhecimento interligado; rendimento; Abertura para a diversidade; Esforço acadêmico; Entendimento de ciência e tecnologia; e Habilidades analíticas. (CABRERA, 2010, p. 54).

\section{Vozes da interlocução}

Para qualificar a interlocução que fazemos entre teoria e prática desses seminários, trazemos para este texto falas de doutorandas e de mestrandas, as quais frequentaram essa disciplina em diferentes momentos e nos surpreendemos com o escopo por elas apontado. A partir do questionamento da importância do Seminário na elaboração da tese ou da dissertação, foi produzida uma categorização de suas respostas, da qual destacamos:

... contribuição ao conhecimento e à inserção na área de conhecimento. O campo cientifico é desvelado. compreensão teórica das relações de força dos campos científicos foram abordados e contribuíram de forma exponencial na construção do estado de conhecimento de minha tese. A apresentação da representatividade dos campos científicos com seus vértices de poder e mecanismos de força simbólica propiciaram um despertar e um interesse no aprofundamento do tema e a compreensão da legitimidade cientifica e das estratégias dos agentes e das instituições. 
Pensar na perspectiva dos campos científicos, nos suscita a movimentar uma nova maneira de perceber o contexto do ensino superior. Como mobilizamos os saberes científicos e suas faces na arte de ensinar e das possiblidades concretas que são veiculadas para o aprendizado.

... a construção do objeto de pesquisa, seus limites e possibilidades.

O Estado de Conhecimento possibilita uma visão ampla e atual dos movimentos da pesquisa ligados ao objeto da investigação que pretendemos desenvolver. É, portanto, um estudo basilar para futuros passos dentro da pesquisa pretendida. Permite-nos entrar em contato com os movimentos atuais acerca do objeto de investigação, oferecendo-nos uma noção abrangente do nível de interesse acadêmico e direcionando, com mais exatidão, para itens a ser explorados - reforço de resultados encontrados ou criação de novos ângulos para o tema de estudo - abrindo assim, inúmeras oportunidades de enriquecimento do estudo. Nesse sentido, a construção do Estado de Conhecimento, fornece um mapeamento das ideias já existentes, dando-nos segurança sobre fontes de estudo, apontando subtemas passíveis de maior exploração ou, até mesmo, fazendo-nos compreender silêncios significativos a respeito do tema de estudo. Acredito que o Estado de Conhecimento deva ser o movimento inicial de toda pesquisa, uma vez que localiza e norteia os passos da investigação, a partir do conhecimento e da compreensão da produção intelectual que aborda estudos relacionados ao objeto de nossa pesquisa.

Ao desenvolver minha pesquisa de doutorado, encontrei, no exercício de construção do Estado de Conhecimento, o delineamento de possibilidades de organização do estudo. Tomar ciência da produção acadêmica que contemplava minha intenção inicial de pesquisa, foi decisivo para aprimorar minhas referências e apontar rumos que até então desconhecia. A análise dos trabalhos e artigos existentes, nos mais variados canais de produção acadêmica, forneceu-me uma visão panorâmica, abrangente e atual, permitindo-me 'desenhar' a estrutura da pesquisa de forma mais coerente e consistente.

.. a relação do campo com o espaço tempo político governamental.

Nas últimas décadas, houve um significativo movimento de expansão de programas, cursos, seminários, encontros, na área de educação em seus diferentes aportes. Proliferam dissertações, teses, artigos, enfim, inúmeros estudos e publicações sobre os aspectos que envolvem a educação e a gestão da educação. Assim, o campo do conhecimento, principalmente no que concerne à pesquisa, não está limitado, determinado, e mesmo ao término de uma pesquisa ainda há muito a ser estudado, aprofundado, discutido e analisado. 
É um movimento cíclico e, por diversas vezes, espiralado, num movimento de claro e escuro, conforme Kosik (1995), e não de forma sequencial, cartesiana e linear. Por si só os dados não têm voz, logo não falam por si só.

... o ato de escrever e as reflexões sobre sua relação com a construção da pessoa

(Re)pensar o momento da escrita da tese é um desafio, pois faz a aventura de adentrar no mundo da pesquisa ser (re)vivida, com seus muitos significados. Pesquisar e materializar nossos achados através da escrita pode ser um prazer, mas também pode mexer com nossos demônios secretos! Este ato transita no limiar entre o sagrado e o profano, pois tudo depende da intencionalidade e do lugar de quem se autoriza a pesquisar.

Talvez, vocês concordem comigo que há similaridade entre pesquisar e viajar, pois ambas requerem planejamento e organização prévios, disciplina para dar conta do roteiro pretendido e ao mesmo tempo, é necessária flexibilidade para viver estas experiências. E o que já foi escrito, pesquisado por outros auxilia e encoraja a compreensão da historicidade do tema que nos instiga e por vezes até assombra em noites mal dormidas, de estudo e de uma boa dose necessária de solidão.

Em meio a minha gula livresca (QUIVY, CAMPENHOUDT, 1988), que me acompanhou no primeiro ano de Doutorado em Educação, me deparei com a disciplina Construindo o estado de conhecimento de sua dissertação/tese. Foi um momento ímpar! Através das atividades desenvolvidas nesta disciplina e claro com o olhar atento, amoroso no dizer freireano e rigoroso da orientadora, consegui avançar no processo de delimitar e de clarear minha temática de estudo ...

O reconhecimento da historicidade da produção no campo cientifico.

A educação e a própria gestão se situam historicamente como prática sociais e que seus conhecimentos são concebidos como construções socioculturais, associo-me a Vygotsky (1978) ao propor que, 'o passado e o presente são vistos à luz da história' (p. 64), pois acredito ser extremamente relevante compreender a historicidade da temática a ser estudada, bem como a produção existente, considerando que a História demanda ser entendida como contexto espaço-temporal no qual o homem constrói suas experiências e vivências de forma significativa. O trabalho desta disciplina é antes de tudo um resgate e valorização do conhecimento produzido, traz possibilidades não somente pela vastidão de produções que encontrei no Banco de Teses e Dissertações da Capes e na RBPAE on line, mas paralelamente oportuniza o movimento 
de junção deste material. Inspira o exercício do olhar, na busca de analisar centenas de produções através da leitura flutuante, de modo a fomentar a busca de lacunas na produção existente. A leitura flutuante é entendida como um a busca de estabelecer o contato com os documentos a analisar e conhecer o texto, deixando-se invadir por impressões e orientações.

O depoimento acima nos remete a Mills (s/d) em sua proposição do "artesão intelectual", "tipo ideal", no sentido weberiano de algo que não é encontrado em forma "pura" na realidade social, mas que, construído pelo pesquisador. Quando a depoente afirma ver no trabalho de pesquisa um ofício ressalta a importância da dimensão existencial na formação do pesquisador ... trata-se de enfatizar a indissociabilidade, para o "artesão intelectual", entre sua vida e seu trabalho.

... a construção coletiva.

Embora a escrita da tese seja um ato solitário, o exercício de construirmos mini bancos de dados proposto por esta disciplina é solidário. Fomenta aproximação não somente com os colegas que possuem afinidade temática, mas também com os que estudam os mais variados temas. Assim, nos oferece, mesmo que minimamente, um panorama da riqueza de objetos de pesquisa.

Acredito também que amplia o olhar sobre a produção científica ao mesmo tempo que nos mobiliza para a produção de conhecimento de forma a contribuir para o avanço da Ciência. Permite nosso mergulho em uma dimensão coletiva de pesquisa, ou seja, nos mobiliza a olhar os problemas de investigação para além das nossas inquietações individuais.

... a quebra dos pré-conceitos e das certezas.

Sou grata ao muito que aprendi nesta disciplina, na convivência com os colegas e com a professora. Este é um momento primordial que dá início a uma organização de ideias, conceitos, ..., e de muita disciplina para além da escrita-resultado. Mas, mexe com as dúvidas e com as certezas, não é apenas um exercício intelectual e acadêmico, enfim é para a vida.

A disciplina Estado do Conhecimento foi fundamental para 'adentrar' no campo de pesquisa e definir o objeto de investigação. 
Acredito que contribuiu para a análise de que está sendo produzido no nosso campo: que temáticas têm sido priorizadas, quais as lacunas, os "silêncios", o que está sendo produzido nas instituições no país e linhas de pesquisa; que referencias teóricos e metodológicos são utilizados.

Outro fator importante é que nos insere numa efetiva prática de pesquisa num movimento de indissociabilidade teoria e prática. Os conhecimentos construídos na disciplina são mobilizados em outros momentos da formação e atuação docente, não se restringindo a uma disciplina pontual.

Na minha avaliação a disciplina deveria constituir o grupo das disciplinas obrigatórias e ser cursada no primeiro semestre do Mestrado/DO.

... a metodologia no olhar do estudante. Reflexões...

Essa disciplina é fundamental para ajudar a constituir a fase exploratória de nossa pesquisa, mas suas contribuições se estendem também à etapa da construção da problemática e do modelo de análise.

No que diz respeito à fase exploratória, sua contribuição é ímpar porque nos dá uma visão do que já foi/está sendo produzido em relação ao objeto de estudo que selecionamos como tema de pesquisa; disso decorre que é possível construir uma avaliação do grau de relevância e da pertinência do tema inicialmente selecionado situando-o em um campo de produção de conhecimento. Desse movimento, emerge outro, que é o acesso e a busca por outros artigos/trabalhos relacionados ao nosso tema, através da consulta às bibliografias daqueles trabalhos selecionados para a construção do estado de conhecimento. De certa forma, esse trabalho, para o qual somos preparados, enquanto estudantes de stricto sensu, também ajuda na contextualização do objeto de estudo, que sempre deve ser situado no contexto histórico, social, mas também no campo científico com o qual se relaciona. A construção da problemática.

Para além da fase exploratória, o estudo, a análise e o cotejamento dos resultados e das análises que emergem dos trabalhos selecionados ajudam a orientar a construção do nosso modelo de análise e nos inspiram também para a organização de possíveis categorias, que representam algumas de nossas hipóteses a priori, elementos que serão necessários tanto na construção da problemática quanto na coleta e interpretação de dados. Se por um lado precisamos ir "a campo" com uma visão aberta e receptiva ao inesperado, ao não planejado, o que enriquece nossas possibilidades de contribuição para a produção de conhecimento do campo, por outro, precisamos fazê-lo nos situando em um quadro teórico e metodológico de referência, que esteja inicialmente delineado, pois é preciso uma direção inicial, uma questão de pesquisa que contribua para a unidade do trabalho, desde o início até seu final. 
... a finalidade no olhar do estudante.

Nessa direção, essa disciplina também é relevante porque permite que tracemos um rumo ou direcionamento nas nossas escolhas, porque nunca partimos neutros ou sem intencionalidades quando iniciamos a etapa da construção das investigações.

Enfim, percebi que a disciplina propicia um movimento de síntese sobre o que está consolidado em cada campo do conhecimento e o que constitui temas emergentes, para os quais há ainda espaço de investigação e questões relevantes em aberto. Também possibilita uma reflexão crítica sobre os questionamentos propostos na fase inicial. Esse movimento de síntese possivelmente ajudará o pesquisador a recolocar o seu problema de pesquisa, na perspectiva assinalada por Quivy e Campenhoudt (1988).

As autoras deste texto buscando refletir sobre todo o processo reconhecem que é um exercício de reflexão pelo qual, na primeira aula, os alunos se perguntam como seria possível realizar a descontrução de um projeto já construído e pelo qual foram selecionados para cursar o Pós-graduação. Por sua vez a professora olha seus alunos e se questiona: Será que eles conseguirão descontruir e construir um novo objeto, já então na estrutura do campo cientifico?

Durante o desenrolar da disciplina lembramo-nos de Wright Mills (s/d) quando afirmava que a pesquisa é um artesanato intelectual, referindo-se ao encaixe de peças para compor o texto final. Algo que caracteriza a imaginação sociológica e que liga o sujeito a sua existência social.

a imaginação sociológica ... consiste em parte considerável na capacidade de passar de uma perspectiva para outra, e, nesse processo, consolidar uma visão adequada de uma sociedade total e de seus componentes. É essa imaginação, é claro, que distingue o cientista social do mero técnico. Técnicos adequados podem ser instruídos em poucos anos. A imaginação sociológica também pode ser cultivada; por certo ela raramente ocorre sem muito de trabalho, muitas vezes rotineiro. Há, no entanto uma qualidade inesperada em relação a ela, talvez porque sua essência seja a combinação de ideias que ninguém supunha que fossem combináveis ... Há um estado de espírito lúdico por trás desse tipo de combinação, bem como um esforço verdadeiramente intenso para compreender o mundo, que em geral falta ao técnico como tal (p. 41).

No desenrolar da disciplina o exercício da produção coletiva, da descoberta que seu tema pode ser não tão inovador como pensado, nem tão atual e nem tão embasado em autores considerados os qualificados, mas também, 
durante o desenrolar da disciplina, ocorre, paralelamente, a descoberta que o "mingau se come pelas beiradas"4, que se aprende a conhecer o campo, que as bibliografias utilizadas no já produzido muito podem auxiliar a nossa própria construção. E, finalmente, ao encerrar a disciplina, que não tem na entrega dos conceitos finais o seu término, nos deparamos com rostos prazerosos pela construção do objeto da tese ou dissertação. Sim, nos conseguimos construir uma problemática inserida no campo da educação. Ela será aprimorada, mas os primeiros passos estão dados.

E, uma certeza permanece: esse habitus bourdieuno, foi construído para outras produções.

Nessa perspectiva, a interação de orientadores de mestrandos e doutorandos que frequentam essa disciplina também são testemunhos importantes da relevância do trabalho que é realizado. A experiência com a orientação exige uma relação pedagógica crítica permeada pelo diálogo como um caminho permanente de construção e de reconstrução de relações humanas e de relações com o conhecimento existente e o conhecimento novo (SHOR; FREIRE, 1987).

Nesse percurso, tem sido possível perceber as aprendizagens feitas em relação ao desenvolvimento da capacidade de escrita com produção de sentido, que tende a favorecer a autonomia intelectual e ao sentimento de pertença a um grupo de discussão/estudos, o que pode configurar o difícil e necessário de convivência entre gentes. Aprende-se a escrever escrevendo, e especialmente, na abordagem qualitativa da pesquisa torna-se requisito essencial para análise de dados coletados e própria explicitação das conexões entre os elementos que constituem uma dissertação ou tese.

\section{Algumas considerações à guisa de conclusão}

Ao retomarmos nossa trajetória como professoras, membros de bancas de mestrado ou doutorado e orientadoras de teses e de dissertações, na interlocução que realizamos, têm sido possível perceber uma qualificação da escrita acadêmica. Percebemos também uma articulação maior entre a problematização, o referencial teórico e o processo de análise dos achados - nesse processo, especialmente no caso das defesas finais.

Com a perspectiva de Walter Benjamin de que "o acontecimento lembrado é sem limites, porque é apenas uma chave para tudo que veio antes e depois", fizemos essa pequena inserção empírica no sentido de acrescentar outras vozes na interlocução que viemos fazendo. Conscientes dos limites e desafios que precisamos assumir para aprofundamento deste tema, ficou para nós que: "escrever é isso aí: interlocução", tal como aprendemos com Mário Osório Marques.

4 Expressão gaúcha que significa irmos com cuidado ao centro do objeto, dominando o conhecimento que circunda o objeto, ou seja, aos poucos vamos tomando contato com os temas relacionados ao nosso objeto de estudo e ao campo epistemológico. 


\section{Referências}

BARDIN, L. Análise de conteúdo. Lisboa: Ed. 70, 1979.

BOURDIEU, P. O campo científico. In: ORTIZ, Renato (Org.). Pierre Bourdieu: sociologia. São Paulo: Ática, 1983. p. $122-155$.

CABRERA, A.; LA NASA. Práticas na sala de aula: a aprendizagem de 10 lições. In: AUDY, J.; MOROSINI, M. C. Inovação e qualidade da Educação Superior. Porto Alegre: Edipucrs/CAPES/CNPq/INEP, 2008. p. 44-74. Disponível em: <vhttp://www.pucrs. br/edipucrs/inovacaoequalidade.pdf>. Acesso em: 12 fev. 2014.

LOVITTS, B. E. Making the implicit explicit: creating performance expectations for the dissertation. Virginia: Stylus, 2007.

FERNANDES, C. M. B. Sala de aula universitária - ruptura, memória educativa, territorialidade - o desafio da construção pedagógica do conhecimento. Tese (Doutorado) - Programa de Pós-Graduação em Educação, FACED/UFRGS, Porto Alegre, 1999.

FERNANDES, C. M. B. Bases epistemológicas e pedagógicas da construção pedagógica do conhecimento. Texto de discussão na disciplina Metodologia do Ensino Superior do Programa de Pós-Graduação da Pontifícia Universidade Católica do Rio Grande do Sul. Porto Alegre, 2011. [mímeo]

KOSIK, K. Dialética do concreto. Rio de Janeiro: Paz e Terra, 1995.

MARQUES, M. O. Escrever é preciso: o princípio da pesquisa. 4. ed. Ijuí: Ed. Unijuí, 2001.

MILLS, W. Sobre o artesanato intelectual e outros ensaios. Rio de Janeiro: Zahar, [s/d].

MOROSINI, M. C. Estado de conhecimento: sua contribuição à ruptura de pré-conceitos. Revista de Educação da UFSM, Santa Maria: Centro de Educação, v. 40, 2015. [aceito para publicação]

QUIVY, R.; CAMPENHOUDT, L. V. Manual de investigação em ciências sociais. Lisboa: Gradiva, 1988.

VYGOTSKY, L. Interaction between learning and development. In: Mind and Society. Harvard: University Press, 1978.

\section{Endereço para correspondência:}

Marília Costa Morosini

Av. Ipiranga, 6681 - Prédio 15, sala 229

90619-900 Porto Alegre, RS, Brasil

E-mail: <marilia.morosini@pucrs.br>

Recebido em: jul./2014

Aceito em: jul./2014 